\title{
Aquisição de estruturas com subida de clítico em português europeu
}

\author{
Inês Vitorino \& Maria Lobo
}

\author{
FCSH-Universidade NOVA de Lisboa/CLUNL
}

\begin{abstract}
:
We present data from an elicited production task and from spontaneous production to investigate the development of clitic climbing by European Portuguese speaking children. We show that clitic climbing is acquired early, that children are sensitive to the presence of proclisis triggers that favour clitic climbing, and that there is development of the knowledge of the verbs that allow clitic climbing. Taking into account the developmental patterns that show an early preference for clitic climbing, we discuss the notion of complexity in child language.
\end{abstract}

Keywords: clitic climbing, language acquisition, complexity, European Portuguese

Palavras-chave: subida de clítico, aquisição da linguagem, complexidade, português europeu

\section{Introdução}

A subida de clítico é um dos fenómenos em que há variação entre línguas. Línguas como o português europeu, o italiano ou o espanhol permitem, em alguns complexos verbais, que o clítico esteja adjacente quer ao verbo não finito que o seleciona, quer ao verbo finito, sendo esta última estrutura chamada "subida de clítico" (1b). Línguas como o francês, em contrapartida, não aceitam que o clítico suba para o domínio finito superior $(2 b)$.

(1) a. O menino quer lavar-se.

b. O menino quer-se lavar.

(2) a. L'enfant veut se laver.

b. *'enfant se veut laver.

Este fenómeno, sujeito a parametrização, tem sido estudado numa perspetiva comparada e numa perspetiva diacrónica, frequentemente em relação com as estruturas chamadas de restruturação (e.g. Rizzi, 1982; Kayne 1989; Gonçalves 1999; Martins 2000; Cardinaletti \& Schlonsky, 2004; entre outros). Há, contudo, poucos estudos que considerem a forma como esta propriedade é adquirida. Este trabalho procura contribuir para o conhecimento da aquisição do fenómeno de subida de clítico no português europeu, considerando dados de um teste de produção induzida e de produção espontânea.

Em particular, procuramos verificar: i) se a possibilidade de subida de clítico é adquirida cedo, como acontece com outros parâmetros (Wexler, 1998) e como descrito para o espanhol (Eisenchlas, 2003; Rodríguez Mondoñedo, Snyder \& Sugisaki, 2006); ii) se há desenvolvimento relativamente aos contextos em que a subida de clítico é permitida; iii) se, nos contextos em que a subida é opcional, há preferência pela subida ou pela não subida; iv) se a presença de negação no domínio superior facilita a subida, tal como descrito para a gramática adulta (Fiéis, Madeira \& Xavier, 2013). Pretendemos ainda determinar de que forma 
os padrões de aquisição que encontramos são compatíveis com diferentes hipóteses teóricas relativas ao fenómeno de subida de clítico e permitem discutir a noção de complexidade no desenvolvimento linguístico. ${ }^{1}$

O artigo está estruturado da seguinte forma: na secção 2, fazemos o enquadramento teórico do fenómeno de subida de clítico, considerando diferentes propostas teóricas, e revendo os trabalhos já existentes sobre a aquisição de colocação de clíticos em diferentes línguas; na secção 3, apresentamos o estudo experimental que realizámos e que consistiu na produção induzida de clíticos em diferentes contextos com complexos verbais; na secção 4, apresentamos dados relativos à produção de clíticos em complexos verbais a partir de um corpus de produção espontânea, incluindo dados de crianças e de adultos (fala dirigida à criança); na secção 5, discutimos os resultados obtidos; e, finalmente, na secção 6, apresentamos as principais conclusões do trabalho.

\section{Enquadramento}

\subsection{Subida de clítico: caracterização}

Como referido acima, o português é uma língua em que pode haver subida de clítico. Isto quer dizer que os clíticos podem cliticizar ao verbo finito da oração superior (3b), em vez de virem adjacentes ao verbo não finito de que são complemento (3a):

(3) a. Queres dar-me o livro?

b. Queres-me dar o livro?

A possibilidade de subida de clítico está sujeita a variação interlinguística: línguas como o português (4), o espanhol (5) e o italiano (6) aceitam subida de clítico, ao passo que línguas como o francês (7) não a aceitam:

(4) a. O menino pode dar-te o livro.

b. O menino pode-te dar o livro.

(5) a. El niño puede darte el libro.

b. El niño te puede dar el libro.

(6) a. Il ragazzo può darti il libro

b. Il ragazzo ti può dare il libro.

(7) a. Le garçon peut te donner le livre.

b. *Le garçon te peut donner le livre.

Note-se que a opcionalidade de subida de clítico só se verifica em complexos verbais com formas não finitas infinitivas ou gerundivas. Em complexos verbais com particípios passados (tempos compostos, por exemplo), a subida é obrigatória em qualquer uma destas línguas, incluindo o francês, podendo considerar-se que o domínio participial é efetivamente um domínio defetivo incapaz de albergar o clítico:

(8) a. O menino tinha-te dado o livro.

b. *O menino tinha dado-te o livro.

(9) a. El niño te ha dado el libro.

b. *El niño ha dadote el libro.

\footnotetext{
${ }^{1}$ Este trabalho foi inicialmente realizado no âmbito da dissertação de mestrado de Inês Vitorino (Vitorino, 2017). Esta nova versão apresenta alterações substanciais relativamente a esse trabalho, em particular no enquadramento e discussão dos resultados.
} 
(10) a. Il ragazzo ti ha dato il libro.

b. *Il ragazzo ha dadoti il libro.

(11) a. Le garçon t'avait donné le livre.

b. *Le garçon avait te donné le livre.

Para além de condições sintáticas de legitimação de subida, são necessárias determinadas condições lexicais. A subida de clítico só é legítima com um subconjunto de verbos (verbos auxiliares e verbos de restruturação), não sendo geralmente aceite com outros verbos (12b):

(12) a. Decidiu dar-me o livro.

b.??Decidiu-me dar o livro.

Há, assim, um conjunto de verbos que aceitam a subida, entre os quais estão os verbos auxiliares temporais, aspetuais e modais que selecionam infinitivo (ir, estar a, poder) e um subconjunto de verbos de controlo (e.g. querer), por exemplo, e outro conjunto de verbos que não aceitam ou desfavorecem a subida, como é o caso de decidir ou esperar. ${ }^{2}$

Em línguas como o português, a subida de clítico é geralmente opcional com verbos de restruturação. Há, contudo, alguns fatores que parecem condicionar a preferência pela subida relativamente à não subida, referidos, por exemplo, em Fiéis \& Madeira (2012) e Fiéis, Madeira \& Xavier (2013), entre os quais estão o tipo de clítico (acusativo de terceira pessoa vs. outros clíticos) e a presença de proclisadores: ${ }^{3}$

(13) a. O Pedro pode lavá-lo.

a'. ?O Pedro pode-o lavar.

b. O Pedro pode lavar-se.

b'. O Pedro pode-se lavar.

(14) a. ?O Pedro não pode lavar-se.

b. O Pedro não se pode lavar.

Ainda que não tenha sido dada ainda uma explicação convincente para estas preferências, tratando-se essencialmente de uma observação descritiva, os falantes têm juízos claros relativamente ao efeito que fatores como o tipo de clítico e a presença de proclisador desempenham na preferência pela subida de clítico.

É relevante acrescentar-se que, ainda que a subida de clítico seja opcional e frequente na produção oral, algumas perspetivas normativas consideram que a não subida é um padrão mais "correto" e desaconselham a subida. Trata-se, pois, de um fenómeno que pode ser condicionado por variáveis sociolinguísticas e estilísticas.

A subida de clítico está geralmente associada a contextos chamados de restruturação, ainda que a sua ocorrência nestas construções não seja obrigatória (Cardinaletti \& Schlonsky, 2004). Isto significa que os verbos que aceitam subida de clítico também aceitam geralmente outros fenómenos que apontam para que o domínio encaixado e o domínio superior formem uma unidade sintática, como movimento longo de objeto (15a) ou, em línguas como o italiano, mudança para o verbo auxiliar essere (Rizzi, 1982). A defetividade do domínio encaixado é suportada pelo facto de as estruturas com subida de clítico e presença de negação no domínio encaixado darem origem a frases agramaticais (15b) (Gonçalves \& Matos, 2008). Assume-se, assim,

\footnotetext{
${ }^{2}$ Como mostram Fiéis, Madeira \& Xavier (2013), há variação entre os falantes quanto à aceitação de subida de clítico com estes verbos.

${ }^{3} \mathrm{O}$ ponto de interrogação nos exemplos (13) e (14) indica que esta ordem é geralmente menos bem aceite do que a outra.
} 
geralmente, que as construções com subida de clítico são mais defetivas do que as construções em que o clítico se mantém no domínio encaixado.

(15) a. Tencionam-se usar todos os recursos disponíveis neste projeto.

b. *O João tenciona-te não contar a história. ～(Duarte, 2003: 646)

$\mathrm{Na}$ secção seguinte, apresentamos resumidamente diferentes propostas teóricas relativas à subida de clítico, bem como alguns dos problemas que lhes têm sido apontados.

\subsection{Subida de clítico: hipóteses teóricas}

\subsubsection{Subida de clítico e parâmetro do sujeito nulo}

De forma a dar conta da variação encontrada em línguas românicas relativamente à gramaticalidade das estruturas com subida de clítico, Kayne (1989) propõe que existe uma correlação entre subida de clítico e fixação positiva do parâmetro do sujeito nulo. Esta correlação parte da observação empírica de que português, italiano e espanhol, línguas de sujeito nulo, permitem subida de clítico, enquanto o francês, língua de sujeito obrigatório, não permite subida de clítico. De acordo com o autor, a subida de clítico estaria relacionada com a capacidade de o nó funcional flexão em línguas de sujeito nulo L-marcar o domínio infinitivo. ${ }^{4}$

Ainda que seja tentador estabelecer uma correlação entre as duas propriedades, existem dados empíricos que põem em causa a proposta de Kayne (1989). Como observa Cinque (2006), não é clara a correlação entre os dois fenómenos. Em primeiro lugar, diacronicamente, os dois fenómenos não mudam necessariamente ao mesmo tempo: Haverkort (1993) e Martins (2000), citando Wanner (1986), referem que, no século XVII, a subida de clítico em francês é ainda frequente, ao contrário da possibilidade de sujeito nulo, que já se teria perdido um século antes. Houve, portanto, um período intermédio entre o francês antigo, língua de sujeito nulo com subida de clítico, e o francês contemporâneo, língua de sujeito obrigatório sem subida de clítico, em que existia subida de clítico sem haver omissão do sujeito. Em segundo lugar, como refere Haverkort (1993), existem línguas tipologicamente distintas em que há subida de clítico, mas não omissão do sujeito: é o caso das línguas Kru, faladas na Costa do Marfim. A hipótese de Kayne, que pressupõe que uma língua com subida de clítico tenha sujeitos nulos, não dá conta destas variedades linguísticas.

Para além disso, vários autores, entre os quais Haverkort (1993), Martins (2000) e Cinque (2006), apontam uma série de problemas teóricos à análise de Kayne (1989), como o conceito de Restrição de Movimento de Núcleo (Head Movement Constraint) que adota e a sua explicação para a forma como a Negação bloqueia a subida de clítico.

\subsubsection{Subida de clítico e defetividade do domínio encaixado}

O fenómeno de subida de clítico tem sido explorado no contexto das construções de restruturação. Vários autores relacionam a possibilidade de subida de clítico com propriedades do domínio não finito, defendendo que as estruturas em que há subida de clítico são, de alguma forma, mais defetivas, ao contrário de autores como Kayne (1989), que defendem a bioracionalidade da construção.

Neste conjunto de propostas encontram-se: i) as que defendem que as construções de restruturação são domínios mono-oracionais (e.g. Rizzi, 1982 e Cinque, 2006, entre outros); ii) as que defendem que o domínio infinitivo é funcionalmente mais defetivo, podendo, segundo alguns autores, haver diferentes graus de defetividade (e.g. Gonçalves, 1999, Martins, 2000, e Wurmbrand, 2001). A defetividade pode passar pela não

\footnotetext{
${ }^{4}$ A noção de L-marcação (marcação lexical) é uma noção usada no enquadramento teórico da Teoria da Regência e da Ligação, que corresponde, em traços gerais, à capacidade de marcação temática por um núcleo lexical que pode fazer com que um domínio deixe de funcionar como barreira.
} 
projeção de categorias funcionais, como $\mathrm{C}$ ou $\mathrm{T}$, ou pela defetividade do núcleo $\mathrm{T}$ quanto a alguns dos seus traços. Na análise de Gonçalves (1999), em estruturas de restruturação, T encaixado pode ser defetivo quanto a traços- $\phi$.

O conjunto de propostas que analisa as construções de restruturação como sendo estruturas funcionalmente menos complexas ou mais defetivas levanta questões interessantes do ponto de vista da aquisição. Geralmente, considera-se que a complexidade guia o processo de aquisição, sendo as estruturas menos complexas adquiridas mais cedo do que as estruturas complexas. Importa, contudo, perceber que noção de complexidade está em causa, o que não é uma questão trivial.

Se adotarmos uma noção de complexidade estrutural e se as estruturas com um menor número de núcleos funcionais forem mais simples para a criança, poder-se-á esperar que sejam adquiridas mais cedo. Kirby (2011) propõe que, no processo de aquisição da linguagem, há preferência por estruturas de elevação, com domínios infinitivos mais defetivos e elevação de argumento, em vez de estruturas de controlo, funcionalmente mais complexas com inserção de PRO. No entanto, de acordo com a autora, esta preferência não se deve tanto à defetividade da estrutura, mas antes ao facto de as crianças preferirem estruturas com menos papéis temáticos, que teriam um menor custo de processamento. Na verdade, outros autores têm defendido que as crianças preferem domínios completos a domínios defetivos, havendo preferência por estruturas em que o verbo tem um menor número de argumentos, o que vai contra a ideia de que a menor complexidade estrutural é sempre mais simples para a criança. Santos, Gonçalves \& Hyams (2016), num trabalho que analisa a produção de estruturas infinitivas complemento de diferentes tipos de verbos (causativos, percetivos e de controlo de objeto), mostram que as crianças optam preferencialmente por estruturas infinitivas funcionalmente menos defetivas (em que um sujeito é internamente legitimado num domínio infinitivo), em vez de estruturas em que o verbo matriz seleciona dois argumentos, sendo um deles uma oração infinitiva funcionalmente mais defetiva.

A questão da complexidade associada às estruturas com e sem subida de clítico é, pois, uma questão complexa. É necessário ponderar, para além da natureza do domínio infinitivo envolvido, a questão do movimento do clítico de um domínio encaixado para um domínio superior. Se se assumir uma noção de complexidade já não puramente estrutural, mas que tenha em conta o número de operações de Merge (interno e externo) envolvidas, na linha de Jakubowicz (2011), é plausível supor-se que uma estrutura com subida de clítico é mais complexa do que uma estrutura sem subida de clítico. Esta assunção é, contudo, controversa, uma vez que, por um lado, não é claro que um maior número de operações de Merge (interno e externo) corresponda necessariamente a uma estrutura mais complexa (veja-se a proposta de Kirby (2011), por exemplo), e, por outro lado, pode haver razões independentes para que a criança prefira a adjacência do clítico ao domínio finito. Se a legitimação do clítico junto a um núcleo funcional finito for uma estratégia menos marcada do que a legitimação num domínio não finito, pode haver uma preferência pela estrutura com subida de clítico, independentemente da defetividade do domínio funcional envolvido.

$\mathrm{Na}$ próxima secção, apresentaremos alguns trabalhos que se focaram na aquisição de colocação de clíticos e, em particular, na aquisição de subida de clítico.

\subsection{Aquisição de colocação de clíticos}

Em contextos de aquisição monolingue, o padrão de colocação de clíticos com formas verbais simples é geralmente adquirido cedo em línguas que têm um padrão proclítico generalizado, como o francês, ou em línguas em que a posição pré ou pós-verbal do clítico está dependente de finitude, como é o caso do espanhol, do italiano ou do grego padrão (Guasti, 1993/1994; Wexler, Gavarró \& Torrens, 2004; Hamann, Rizzi \& Frauenfelder, 1996; Grüter, 2006; Marinis, 2000; entre outros). Em (13) e (14), ilustramos este contraste com exemplos do francês e do espanhol, respetivamente: 
(13) a. Jean se lave les mains.

a'. * Jean lave se les mains.

b. Jean est sorti avant de se laver les mains.

b'. *Jean est sorti avant de laver se les mains.

(14) a. Juan se lava las manos.

a'. *Juan lavase las manos.

b.* Juan salió antes de se lavar las manos.

b'. Juan salió antes de lavarse las manos.

A aquisição da colocação de clíticos em português europeu e grego cipriota é, contudo, mais complexa, uma vez que a posição proclítica depende de uma série de propriedades sintáticas não dependentes da flexão, entre as quais a presença de negação: ${ }^{5}$

\section{(15) a. O João lava-se.}

b. O João não se lava.

Relativamente ao grego cipriota, existem também questões sociolinguísticas relacionadas, uma vez que o grego cipriota coexiste com o grego padrão numa situação de diglossia (Agathocleous et al., 2014; Grohmann \& Leivada, 2012). Quanto ao português europeu, vários trabalhos têm mostrado que, ao contrário de outras línguas, a colocação de clíticos é um fenómeno de desenvolvimento tardio, havendo generalização da ênclise em fases iniciais e um desenvolvimento gradual dos contextos de próclise (Duarte, Matos \& Faria, 1995; Duarte \& Matos, 2000; Costa, Fiéis \& Lobo, 2015). De entre os contextos de próclise que os autores consideraram (negação, sujeitos negativos, advérbio pré-verbal já, sujeitos quantificados, orações completivas e orações causais com porque), a negação é o contexto em que a próclise estabiliza mais cedo. Estes trabalhos centraram-se, contudo, apenas em estruturas com formas verbais simples, não tendo investigado contextos com complexos verbais que permitem subida de clítico.

O fenómeno de subida de clítico corresponde a um outro contexto em que há variação na posição que o clítico ocupa internamente a uma mesma língua e que é interessante estudar do ponto de vista do desenvolvimento linguístico. Estes contextos foram já estudados em trabalhos que se centram na aquisição do espanhol como L1, uns baseados em dados de produção espontânea, outros em dados de produção induzida. ${ }^{6}$

Eisenchlas (2003) aplicou um teste de repetição a 71 crianças argentinas falantes monolingues de espanhol, com idades compreendidas entre 3;0 e 6;4, divididas em sete grupos. As estruturas em causa continham complexos verbais com verbos modais que permitiam subida de clítico e incluíam condições com o clítico (objeto direto ou indireto) em ênclise ao domínio infinitivo (V-VInf-Cl) ou em próclise ao domínio finito (Cl-V-VInf), sendo este último padrão um contexto de subida de clítico. A autora verificou diferenças significativas entre a repetição de frases sem subida (ênclise ao verbo infinitivo), com uma média de taxas de acerto de $42 \%$, e a repetição de frases com subida de clítico (próclise ao verbo finito), com uma média de taxa de acerto de $73 \%$. As crianças, em particular as mais novas, têm preferência pela estrutura com subida de clítico, havendo um número considerável de alterações de estruturas V-VInf-Cl para estruturas Cl-V-Vinf (46\% dos erros). O contrário (alteração de Cl-V-VInf para V-VInf-Cl) quase não acontece (6\% dos erros).

\footnotetext{
${ }^{5}$ Para uma revisão minuciosa dos contextos condicionadores de próclise em português europeu, consulte-se Martins (2013).

${ }^{6}$ Para o estudo deste fenómeno na aquisição bilingue, existem ainda o trabalho de Pérez-Leroux, Cuza \& Thomas (2011), que aplica um teste de repetição a dois grupos de bilingues (simultâneos e consecutivos) inglês/espanhol, e o estudo de Hamann \& Belletti (2006), que considera diferentes estruturas com clíticos em dados de produção espontânea de diferentes tipos de bilingues. Ambos os trabalhos identificam fenómenos de transferência.
} 
Face a estes resultados, a autora propõe que a subida pode ser uma operação menos custosa do que a não subida.

Rodríguez-Mondoñedo, Snyder \& Sugisaki (2006) consideram também a subida de clítico na aquisição do espanhol, mas partem da análise de um corpus de produções de 5 crianças, com idades entre 1;4 e 4;8, da base CHILDES. Os autores, assumindo a correlação estabelecida por Kayne (1989) entre subida de clítico e sujeito nulo, procuram verificar se é possível estabelecer uma ligação entre os dois fenómenos na aquisição do espanhol e se a subida de clítico é adquirida cedo, como esperado de uma propriedade paramétrica, na linha de Wexler (1998). Os autores concluem que as crianças produzem subida desde cedo (entre os 2;0 e os 3;10) e que não há nenhuma criança que adquira a ausência de subida significativamente mais cedo do que a subida.

Tanto Eisenchlas (2003), como Rodríguez-Mondoñedo, Snyder \& Sugisaki (2006), ainda que baseados em metodologias distintas, coincidem quanto à precocidade de aquisição de subida de clítico no desenvolvimento monolingue do espanhol.

\subsection{Questões de investigação}

Tendo em conta os estudos referidos nas secções anteriores, propomos, neste trabalho, investigar as seguintes questões:

i) A possibilidade de subida de clítico é adquirida cedo no português europeu?

ii) As crianças são sensíveis à presença da negação como fator facilitador da subida, como acontece na gramática adulta?

iii) Há desenvolvimento relativamente aos verbos que aceitam subida de clítico?

iv) Em contextos de subida opcional, qual das posições é preferida pelas crianças?

Sendo a possibilidade de subida de clítico uma propriedade paramétrica dependente de propriedades do domínio funcional, espera-se que, à semelhança do que acontece no espanhol, seja adquirida precocemente.

Sendo a negação o indutor de próclise que é adquirido mais cedo, pode esperar-se que as crianças sejam sensíveis à presença da negação como elemento facilitador da subida de clítico.

Estando o conhecimento dos contextos de subida de clítico dependente de conhecimento lexical, esperase que possa haver desenvolvimento quanto aos verbos que aceitam subida de clítico.

Sendo a subida de clítico possivelmente uma estrutura funcionalmente mais simples e em que o clítico é legitimado num domínio finito, é plausível que seja preferida à estrutura sem subida de clítico. Contudo, se a associação a um domínio finito ou a maior defetividade funcional não forem estruturas de menor complexidade para a gramática infantil, pode não se manifestar preferência clara por uma das posições.

Para dar resposta às questões enunciadas acima, considerámos dados de um teste de produção induzida, que descreveremos na próxima secção, e dados de produção espontânea, que descreveremos na secção 4.

\section{Subida de clítico: estudo experimental}

\subsection{Desenho experimental}

Para estudar a aquisição de estruturas com subida de clítico, foi construído um teste experimental de produção induzida. O teste incluiu as variáveis presença/ausência de proclisador e tipo de verbo (de subida obrigatória, opcional ou desfavorável). Foram testados 7 verbos: o verbo ter enquanto auxiliar de tempos compostos (ocorrendo com o particípio passado e obrigando, portanto, à subida de clítico), os verbos querer, 
conseguir e ir, enquanto verbos de subida opcional, e os verbos decidir, gostar de e odiar, enquanto verbos de subida desfavorável. ${ }^{7}$

O teste era composto por 28 itens e 5 distratores, com 4 itens por verbo ( 2 em contexto de ênclise e 2 em contexto de próclise). Utilizou-se apenas a negação enquanto proclisador, uma vez que estudos anteriores comprovam que este é o contexto de próclise adquirido mais cedo (cf. Costa, Fiéis \& Lobo, 2015). De forma a minimizar ao máximo a omissão de clítico, induziu-se apenas a produção do clítico se, visto este ser o clítico com menor taxa de omissão em PE, deixando também de ser omitido mais cedo (cf. Costa \& Lobo, 2007).

Veja-se abaixo alguns dos exemplos que constavam do teste:

a) Exemplo de item com o verbo ter em contexto de ênclise:

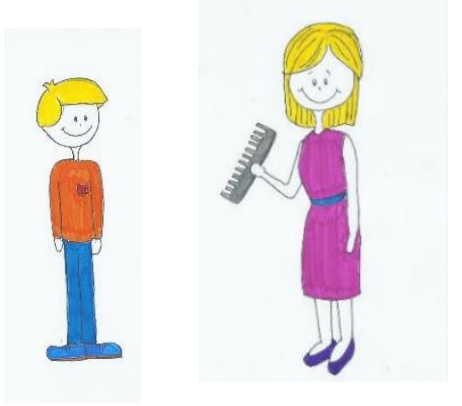

Figura 1

Investigador: A mãe foi ter com o Manuel para lhe dar o pente, mas ele estava penteado. O que é que o Manuel tinha feito antes de a mãe chegar? O Manuel...

Resposta esperada: tinha-se penteado.

b) Exemplo de item com verbo ir em contexto de ênclise:

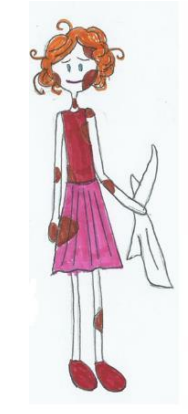

Figura 2

\footnotetext{
${ }^{7}$ Foi utilizado o termo desfavorável, uma vez que em Fiéis \& Madeira (2012) é apresentada uma proposta de gradação na aceitabilidade de construções com subida de clítico segundo a qual nenhum verbo é considerado totalmente impeditivo de subida.
} 
Investigador: A Mariana está toda suja e tem uma toalha na mão. O que é que a Mariana vai fazer com a toalha? A Mariana...

Resposta esperada: vai-se lavar/vai lavar-se.

c) Exemplo de item com verbo decidir em contexto de próclise:

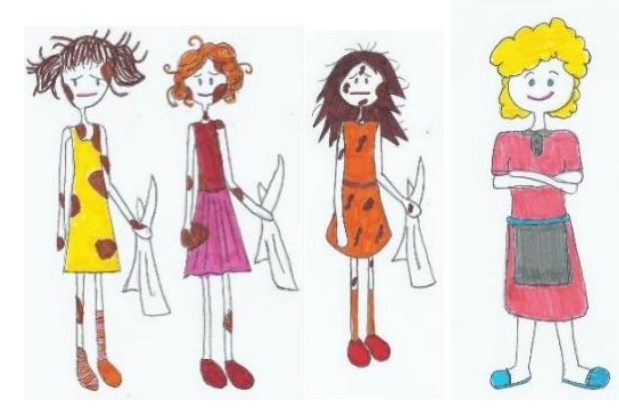

Figura 3
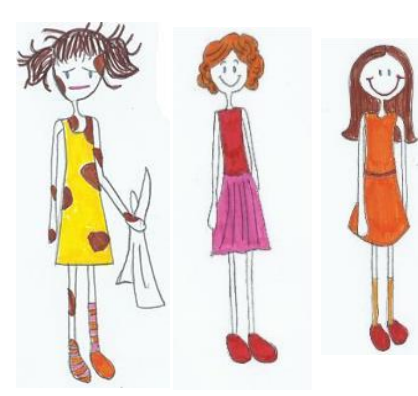

Figura 4

Investigador: Estas meninas estão todas sujas. A mãe deu uma toalha a cada uma. (Figura 3)

Olha, estas duas meninas agora já estão limpas. Mas esta continua suja. (Figura 4)

O que é que ela não decidiu fazer? Ela...

Resposta esperada: não decidiu limpar-se.

\subsection{Participantes}

O teste foi aplicado a 64 crianças falantes nativas de PE, que foram divididas em dois grupos: préescolar (33 crianças de 5 e 6 anos); e escolar (31 crianças com idades entre os 6 e os 8 ). O teste foi, ainda, aplicado a um grupo de controlo composto por 21 adultos com idades compreendidas entre os 20 e os 57 anos:

\begin{tabular}{lccc}
\hline & $\mathbf{N}$ & Intervalo de idades & Média de idade \\
\hline Pré-escolar & 33 & $5 ; 2-6 ; 2$ & $5 ; 9$ \\
\hline Escolar & 31 & $6 ; 2-8 ; 2$ & $7 ; 3$ \\
\hline Adultos & 21 & $20-57$ & 29 \\
\hline \multicolumn{4}{c}{ Tabela 1. Caracterização dos participantes por grupo }
\end{tabular}

Tabela 1. Caracterização dos participantes por grupo

\subsection{Resultados}

Nesta secção, analisamos os resultados do teste de produção induzida.

No gráfico 1, apresentam-se, para cada um dos grupos (pré-escolar, escolar e grupo de controlo), as taxas de subida de clítico com verbos de subida obrigatória (VSOb) (ter), verbos de subida opcional (VSOp) 
(querer, ir, conseguir) e verbos de subida desfavorável (VSD) (decidir, odiar, gostar de), distinguindo os contextos sem proclisador (ênclise) e com proclisador (próclise).

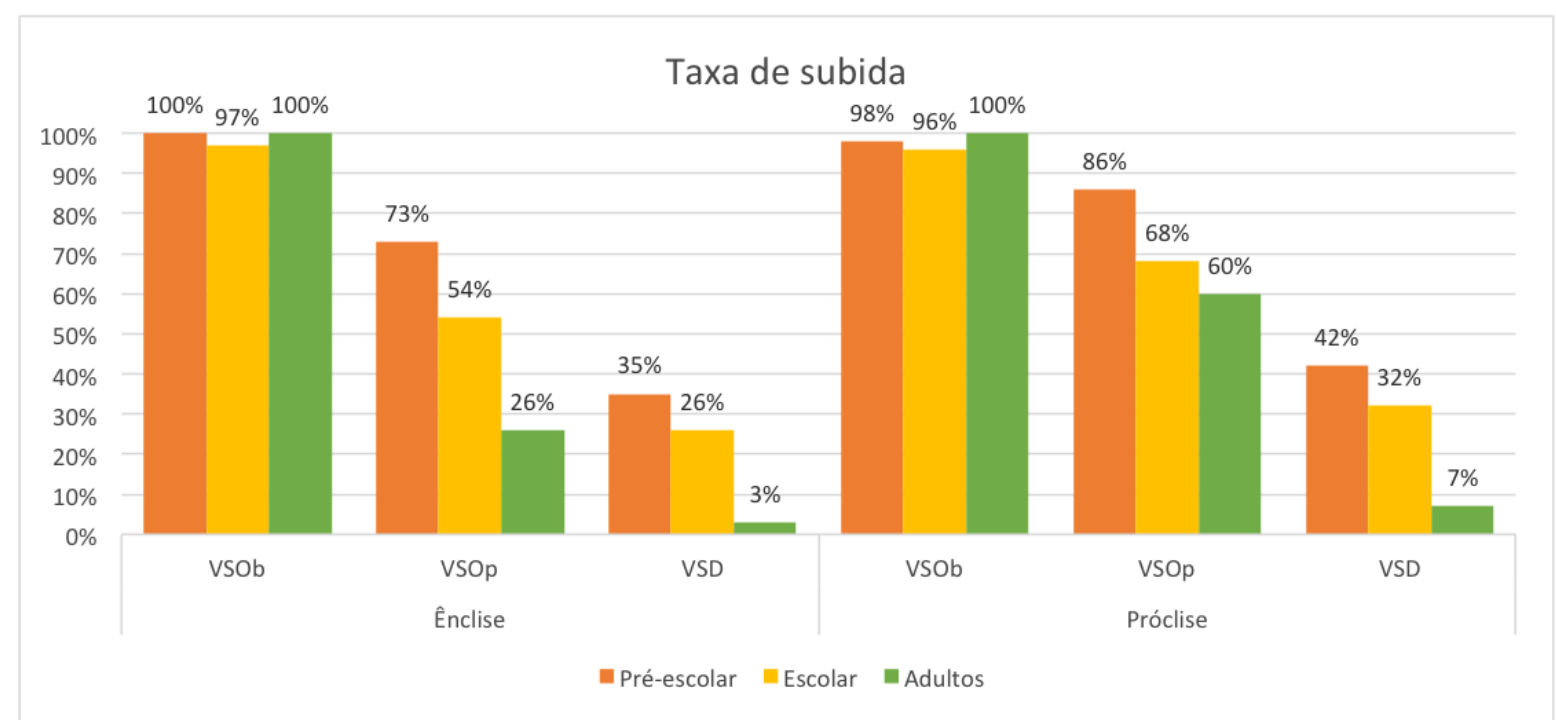

Gráfico 1. Percentagem de subida de clítico para cada tipo de verbo pelos grupos pré-escolar, escolar e de controlo

Nos contextos com verbo de subida obrigatória, verificamos que quer as crianças, quer os adultos produzem de forma (quase) categórica subida de clítico, como esperado, independentemente da presença de proclisador. Apesar de ter havido alguns casos residuais de não subida neste contexto por parte das crianças, pode-se concluir que existe convergência entre a gramática infantil e a do adulto em contexto de subida obrigatória.

Comparando os contextos de verbos de subida opcional com os de verbos de subida desfavorável, estes resultados permitem verificar que todos os grupos fazem distinção entre verbos que permitem a subida e verbos que a desfavorecem, uma vez que os verbos de subida opcional têm sempre percentagens de subida mais elevadas do que os de subida desfavorável. Apesar de haver subida com verbos de subida desfavorável, em todos os grupos, as taxas são bastante mais baixas quando comparadas com as dos verbos de subida opcional, e, nos adultos, a subida com estes verbos é meramente residual.

Analisando as taxas de subida com verbos de subida opcional, podemos verificar que as crianças mais novas optam mais pela subida do que as mais velhas, sendo o grupo de controlo aquele que recorre menos à subida: i) existe uma clara preferência pela subida no grupo pré-escolar; ii) no grupo escolar, a subida continua a ser a opção preferida pelas crianças, apesar de essa preferência não ser tão acentuada; iii) o grupo de controlo mostrou uma clara preferência pela não subida (a percentagem de não subida é mais do dobro da de subida).

Considerando agora a variável presença/ausência de proclisador, podemos observar as taxas de subida e não subida na presença de proclisador - negação - (contexto de próclise) e na ausência de proclisador (contexto de ênclise) em cada um dos grupos. Podemos verificar que a presença do proclisador tem influência no fenómeno, mostrando favorecer a subida. Esta preferência pela subida de clítico na presença de proclisador verifica-se em todos os grupos, o que comprova que existe sensibilidade por parte de adultos e crianças quanto à presença de um atrator de próclise. No grupo dos adultos, há um contraste claro, nos verbos de 
subida opcional, entre contextos com e sem proclisador: a presença de proclisador induz claramente a preferência pela subida de clítico.

Vejam-se agora os resultados por verbo:

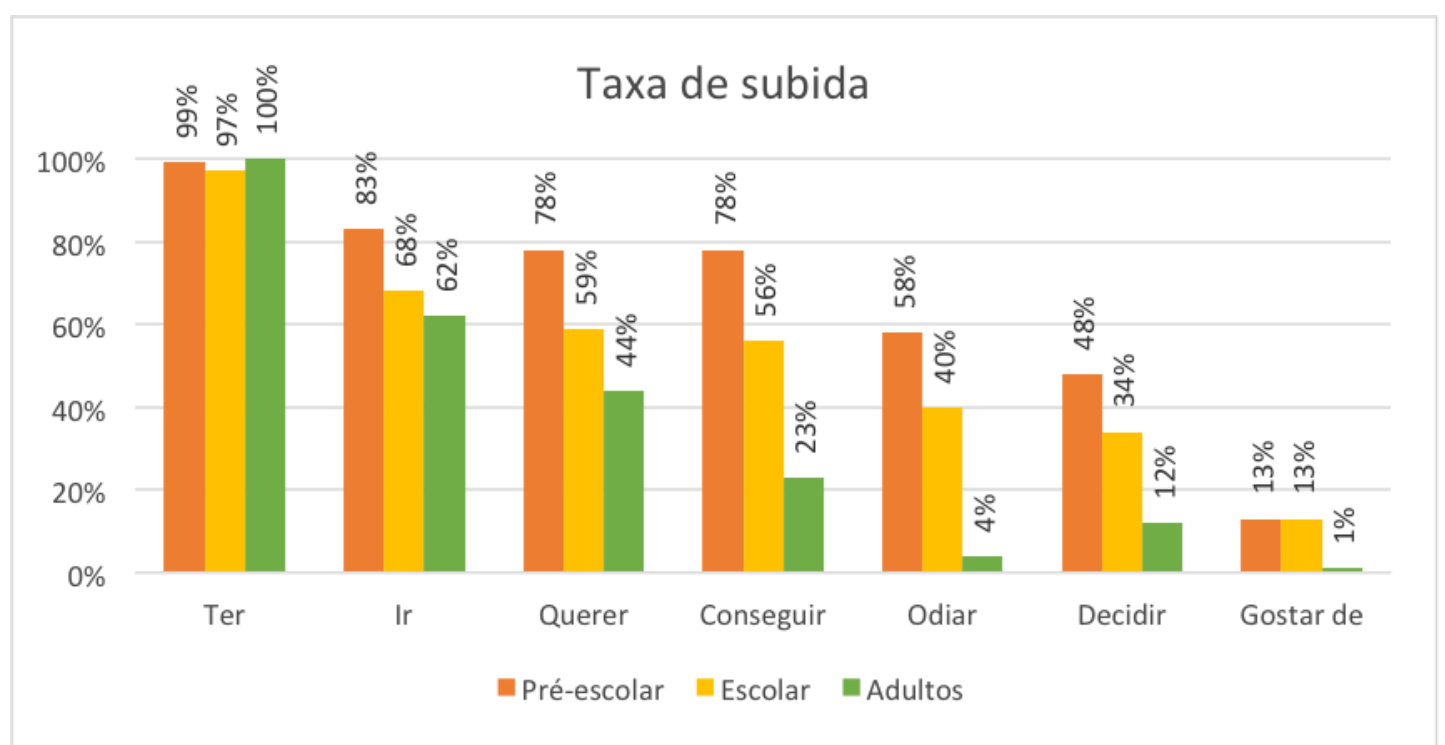

Gráfico 2. Percentagem de subida de clítico com cada verbo nos grupos pré-escolar, escolar e de controlo

Neste gráfico, verifica-se que, em todos os grupos, o verbo de subida opcional com maior percentagem de subida é o verbo ir, seguindo-se o verbo querer e depois o conseguir. ${ }^{8}$ Assim, o verbo semiauxiliar ir é aquele que mais favorece a subida, havendo taxas inferiores de subida com os verbos de controlo de sujeito querer e conseguir.

Dos três verbos de subida desfavorável (odiar, decidir e gostar de), gostar de é aquele que apresenta menos casos de subida em todos os grupos, o que poderá estar associado ao facto de a preposição de inibir a subida, tal como é proposto em estudos anteriores. ${ }^{9}$ Ainda que, no grupo de controlo, a subida com estes verbos seja residual, há uma taxa baixa de subida com todos eles, em particular com o verbo decidir. Para este conjunto de verbos, só no grupo pré-escolar, e apenas com o verbo odiar, encontramos uma percentagem de subida superior à de não subida. Pode considerar-se, no entanto, que há sensibilidade quanto ao tipo de verbo, dado que a percentagem de subida com este verbo é bastante inferior à percentagem de subida com verbos de subida opcional (com estes a subida atingiu um valor de $78 \%$ ou superior, neste grupo).

Observam-se, pois, diferenças nos resultados conforme o tipo de verbo, o que permite concluir que existe conhecimento lexical acerca dos verbos que permitem ou desfavorecem a subida, ainda que esse conhecimento ainda não tenha estabilizado nos grupos infantis.

\footnotetext{
${ }^{8}$ Note-se, no entanto, que as percentagens de subida com o verbo querer e conseguir são idênticas no grupo pré-escolar, correspondendo ambas a $78 \%$.

${ }^{9}$ A percentagem de subida com o verbo gostar de é superior em contexto de próclise nos três grupos. Este resultado pode estar associado à observação de Duarte (2003:857-859), segundo a qual a preposição de permite subida de clítico em contexto de próclise, mas não em contexto de ênclise.
} 
Vejamos agora os resultados individuais dos participantes nos contextos de subida opcional, considerando o número de participantes em cada grupo que só produz subida, nunca produz subida e produz opcionalmente subida em menos de metade dos casos ou em número igual ou superior a metade dos casos:

\begin{tabular}{lcccc}
\hline & Subida categórica & Subida $\mathbf{2 0 0 \%}$ & Subida $<\mathbf{5 0 \%}$ & Ausência de subida \\
\hline Pré-escolar & $15 \%$ & $76 \%$ & $9 \%$ & $0 \%$ \\
& $(5 / 33)$ & $(25 / 33)$ & $(3 / 33)$ & $0 / 33$ \\
\hline Escolar & $9,7 \%$ & $61,3 \%$ & $25,8 \%$ & $3,2 \%$ \\
& $(3 / 31)$ & $(19 / 31)$ & $(8 / 31)$ & $(1 / 31)$ \\
\hline Adultos & $9,5 \%$ & $23,8 \%$ & $66,66 \%$ & $0 \%$ \\
& $(2 / 21)$ & $(5 / 21)$ & $(14 / 21)$ & $(0 / 21)$ \\
\hline
\end{tabular}

Tabela 2. Número e percentagem de participantes em cada grupo que manifestam diferentes padrões - subida categórica, subida facultativa, ausência de subida - com verbos de subida opcional

Como se pode verificar, há variação em todos os grupos, mas quase todos os participantes produzem subida de clítico, ainda que em taxas variáveis: há um único participante (uma criança do grupo escolar) que nunca produz subida. No grupo pré-escolar, a maioria dos participantes prefere a subida. Só $9 \%$ das crianças deste grupo tiveram taxas mais altas de não subida do que de subida. No grupo escolar, embora a maioria dos participantes continue a preferir a subida, há uma taxa superior, relativamente ao grupo pré-escolar, dos que preferem a não subida. No grupo dos adultos, também encontramos variação individual, com um número de participantes que preferem a não subida superior ao dos que preferem a subida.

Vejamos agora (Tabela 3) os resultados individuais com os verbos de subida desfavorável:

\begin{tabular}{lcccc}
\hline & Subida categórica & Subida $\geq \mathbf{5 0 \%}$ & Subida $<\mathbf{5 0 \%}$ & Ausência de subida \\
\hline Pré-escolar & $0 \%$ & $33 \%$ & $64 \%$ & $3 \%$ \\
& $(0 / 33)$ & $(11 / 33)$ & $(21 / 33)$ & $(1 / 33)$ \\
\hline Escolar & $0 \%$ & $22,6 \%$ & $51,6 \%$ & $25,8 \%$ \\
& $(0 / 31)$ & $(7 / 31)$ & $(16 / 31)$ & $(8 / 31)$ \\
\hline Adultos & $0 \%$ & $0 \%$ & $33 \%$ & $67 \%$ \\
& $(0 / 21)$ & $(0 / 21)$ & $(7 / 21)$ & $(14 / 21)$ \\
\hline
\end{tabular}

Tabela 3. Número e percentagem de participantes em cada grupo que manifestam diferentes padrões - subida categórica, subida facultativa, ausência de subida - com verbos de subida desfavorável

Podemos verificar que apenas 7 adultos tiveram algum caso de subida e, em todos eles, tratou-se de um caso pontual; os restantes 14 nunca produziram subida de clítico com verbos de subida desfavorável. Nenhuma criança preferiu a subida com estes verbos, sendo a não subida a opção maioritária quer no grupo pré-escolar, quer no grupo escolar.

\section{Subida de clítico: dados de produção espontânea}

Como complemento aos dados de produção induzida, e de forma a obter dados de crianças mais novas comparáveis com os do estudo de Rodríguez-Mondoñedo, Snyder \& Sugisaki (2006), analisámos dados de produção espontânea. 


\subsection{Metodologia}

Foram analisadas as produções de 3 crianças, com idades entre 1;5 e 3;11, que integram o Corpus Santos, disponível no CHILDES (Santos et al., 2014):

INM: $1 ; 5.9-2 ; 9.3$

INI: $1 ; 6.6-3 ; 11.12$

TOM: $1 ; 6.18-3 ; 10.16$

Analisou-se também a fala dos adultos que interagiam com essas crianças.

Foi feito um levantamento de todas as estruturas com complexos verbais em que ocorrem clíticos (contextos de possível subida de clítico) na fala do adulto e na fala das crianças, tendo-se feito a codificação dos dados por: i) tipo de verbo finito; ii) tipo de clítico (consideraram-se todos os clíticos e não apenas se); iii) posição do clítico (subida / não subida); e iv) presença/ausência de proclisador.

\subsection{Resultados}

Nas produções dos adultos, registaram-se os seguintes verbos em contexto de possível subida de clítico:

andar; andar a; chegar a; começar a; conseguir; continuar a; costumar; dever; estar a; ir; parecer; poder; querer; saber; vir. ${ }^{10}$

Na produção infantil, encontrámos um conjunto mais reduzido de verbos:

dever; estar a ir, poder; querer. ${ }^{11}$

Quanto aos clíticos que ocorrem em contexto de possível subida, identificaram-se clíticos acusativos, dativos e reflexos, de diferentes pessoas gramaticais: alas, lhellhes, me, nos, olos, se, telto, vos.

Na tabela 4, apresentam-se os resultados globais de subida vs. não subida para crianças e adultos:

\begin{tabular}{lcc}
\hline & Subida de clítico & Não subida \\
\hline Crianças & $37 / 59$ & $22 / 59$ \\
& $63 \%$ & $37 \%$ \\
\hline Adultos & $460 / 534$ & $74 / 534$ \\
& $86 \%$ & $14 \%$ \\
\hline
\end{tabular}

Tabela 4. Resultados globais de subida / não subida de clítico nos dados de produção espontânea

Os dados de produção espontânea dos adultos permitem chegar a resultados bastante diferentes daqueles que encontrámos no teste de produção induzida. Enquanto, na produção induzida, a opção preferida pelos adultos foi a não subida, nos dados de produção espontânea verifica-se precisamente o oposto: a percentagem de subida corresponde a $86 \%$, enquanto a de não subida se fica apenas pelos $14 \%{ }^{12}$ No caso das crianças,

\footnotetext{
${ }^{10}$ Há, ainda, ocorrências de estruturas com seleção de complementos infinitivos com os verbos ter, ter delque, escusar de, acabar por e precisar de. Apesar disso, dado que o verbo ter seguido de particípio passado é de subida obrigatória e os restantes são de subida desfavorável, estes não foram analisados.

${ }^{11} \mathrm{O}$ verbo ter de surge numa ocorrência de produção infantil, na qual há subida de clítico, apesar de a presença da preposição de inibir a subida em contexto de ênclise:

i) "Tinha-me de cair." (Tomás: 3;10.6)

${ }^{12}$ Tal poderá, eventualmente, estar associado a uma possível influência da norma, que aconselha a não subida, uma vez que a situação de produção induzida é sempre mais artificial para os falantes. Além disso, é preciso ter em conta que os dados de produção espontânea provêm apenas de 10 falantes.
} 
verificou-se preferência pela subida, apesar de esta não ter sido tão acentuada como na produção induzida (63\% de subida vs. $37 \%$ de não subida).

Relativamente à presença/ausência de proclisador, verificou-se, para os dois grupos, que, à semelhança do observado na produção induzida, a presença de um atrator de próclise favorece a subida. O efeito da presença de um atractor de próclise parece ser maior nas crianças do que nos adultos, que mantêm taxas elevadas de subida quer haja proclisador quer não. É importante considerar, contudo, o facto de os dados das crianças serem em número reduzido, o que pode estar a condicionar os resultados.

\begin{tabular}{lcccc}
\hline & \multicolumn{2}{c}{ Com proclisador } & \multicolumn{2}{c}{ Sem proclisador } \\
\hline & Subida de clítico & Não subida & Subida de clítico & Não subida \\
\hline Crianças & $8 / 8$ & $0 / 8$ & $30 / 51$ & $21 / 51$ \\
& $100 \%$ & $0 \%$ & $59 \%$ & $41 \%$ \\
\hline Adultos & $159 / 162$ & $3 / 162$ & $301 / 372$ & $71 / 372$ \\
& $98 \%$ & $2 \%$ & $81 \%$ & $19 \%$ \\
\hline
\end{tabular}

Tabela 5. Subida de clítico em função da presença/ausência de proclisador na produção espontânea

Quanto aos clíticos analisados, verificou-se que, tanto no grupo dos adultos como no das crianças, excluindo os clíticos de muito baixa frequência, como nos e vos, aqueles que tiveram uma maior percentagem de subida foram os clíticos me e $t e$ :

\begin{tabular}{lcccccccc}
\hline & \multicolumn{4}{c}{ Crianças } & \multicolumn{4}{c}{ Adultos } \\
\hline & Subida de clítico & \multicolumn{2}{c}{ Não subida } & \multicolumn{2}{c}{ Subida de clítico } & \multicolumn{2}{c}{ Não subida } \\
\hline a/as & 0 & 0 & $100 \%$ & $(5 / 5)$ & $25 \%$ & $(3 / 12)$ & $75 \%$ & $(9 / 12)$ \\
\hline lhe/lhes & 0 & 0 & $100 \%$ & $(2 / 2)$ & $81 \%$ & $(69 / 85)$ & $19 \%$ & $(16 / 85)$ \\
\hline $\boldsymbol{m} \boldsymbol{e}$ & $73 \%$ & $(8 / 11)$ & $27 \%$ & $(3 / 11)$ & $90 \%$ & $(152 / 168)$ & $10 \%$ & $(16 / 168)$ \\
\hline $\boldsymbol{n o s}$ & 0 & 0 & 0 & 0 & $100 \%$ & $(1 / 1)$ & 0 & 0 \\
\hline $\boldsymbol{o} / \boldsymbol{o s}$ & $17 \%$ & $(1 / 6)$ & $83 \%$ & $(5 / 6)$ & $86 \%$ & $(6 / 7)$ & $14 \%$ & $(1 / 7)$ \\
\hline $\boldsymbol{s} \boldsymbol{e}$ & $68 \%$ & $(15 / 22)$ & $32 \%$ & $(7 / 22)$ & $85 \%$ & $(88 / 104)$ & $15 \%$ & $(16 / 104)$ \\
\hline $\boldsymbol{t}$ e/to & $100 \%$ & $(12 / 12)$ & 0 & 0 & $90 \%$ & $(140 / 155)$ & $10 \%$ & $(15 / 155)$ \\
\hline vos & $100 \%$ & $(1 / 1)$ & 0 & 0 & $50 \%$ & $(1 / 2)$ & $50 \%$ & $(1 / 2)$ \\
\hline Total & $63 \%$ & $(37 / 59)$ & $27 \%$ & $(22 / 59)$ & $86 \%$ & $(460 / 534)$ & $14 \%$ & $(74 / 534)$ \\
\hline
\end{tabular}

Tabela 6. Subida de clítico em função do tipo de clítico na produção espontânea

Para além de complementar os resultados de produção induzida, os dados de produção espontânea permitiram, ainda, averiguar a precocidade do fenómeno. Com a análise das ocorrências de subida de clítico, verificou-se que a primeira ocorrência de subida nos dados das crianças se situou antes dos 3 anos (Tomás: 2;6; Inês I: 2;8; Inês: 2;10).

\section{Discussão}

Os resultados do teste de produção induzida e da análise dos dados de produção espontânea permitiramnos dar resposta às nossas questões de investigação, que retomamos aqui.

i) A possibilidade de subida de clítico é adquirida cedo no português europeu? 
Os dados de produção espontânea permitem-nos concluir que, tal como para o espanhol (cf. Eisenchlas, 2003; Rodríguez-Mondoñedo, Snyder \& Sugisaki, 2006), a subida de clítico é adquirida cedo no português europeu. Antes dos 3 anos, as crianças já produzem estruturas com subida de clítico. Confirma-se, portanto, que esta é uma propriedade paramétrica de fixação precoce, o que é esperado tendo em conta a hipótese de Wexler (1998) sobre fixação precoce de parâmetros e aquilo que sabemos sobre a fixação de outros parâmetros da gramática, como o parâmetro do sujeito nulo ou a ordem núcleo-complemento, que são fixados cedo (Guasti, 2002; entre outros).

\section{ii) As crianças são sensíveis à presença da negação como fator facilitador da subida, como acontece na} gramática adulta?

Quer os resultados do teste de produção induzida, quer os resultados dos dados de produção espontânea mostram que quer os adultos, quer as crianças de ambos os grupos são sensíveis à presença de proclisador como facilitador da subida de clítico. Na presença de proclisador, todos os grupos têm taxas de subida mais elevadas. Sendo a negação o contexto em que a próclise é adquirida mais cedo (Costa, Fiéis \& Lobo, 2015), não é de admirar que as crianças de 5 anos já sejam sensíveis à presença de negação também nos contextos de subida de clítico. Ainda que não tenhamos uma explicação para este fenómeno, i.e. para o facto de a negação no domínio superior facilitar a subida de clítico, os nossos dados confirmam-no empiricamente, tal como observado em Fiéis \& Madeira (2012) e Fiéis, Madeira \& Xavier (2013).

Para além disso, os dados da produção espontânea apontam para que a natureza morfofonológica do clítico possa desempenhar algum papel na preferência pela subida de clítico, ainda que o número desigual de clíticos de cada tipo não permita retirar conclusões muito seguras.

\section{iii) Há desenvolvimento relativamente aos verbos que aceitam subida de clítico?}

Os dados do teste de produção induzida mostram que a diferença entre os contextos de verbo seguido de particípio passado e os contextos de verbo seguido de infinitivo já está estabelecida. A identificação do domínio participial como um domínio defetivo, incapaz de albergar o clítico, é adquirida cedo. Estes dados confirmam que as propriedades dos clíticos que dependem categoricamente da especificação do domínio funcional, como acontece com a ênclise e a próclise no italiano e no espanhol, são adquiridas cedo.

Pelo contrário, a especificidade dos diferentes domínios infinitivos, sendo uns mais defetivos do que outros, leva algum tempo a estabilizar. Neste caso, não está em causa apenas a aquisição da especificidade do domínio funcional. A identificação dos verbos legitimadores de subida vs. verbos não legitimadores de subida requer desenvolvimento de conhecimento lexical, como defendem Gonçalves (1999) e Wurmbrand (2001), entre outros. Para além de o conhecimento sobre o conjunto de verbos que rejeitam a subida estar sujeito a desenvolvimento, existe também alguma variação na gramática adulta, como mostra o estudo de Fiéis \& Madeira (2012) e como mostram os dados do grupo de controlo no teste de produção induzida.

Outros estudos têm mostrado que construções em que há variação na gramática adulta e que requerem algum desenvolvimento lexical estabilizam mais tardiamente. É o caso da aquisição dos diferentes domínios que desencadeiam a próclise no português europeu, como mostram Costa, Fiéis \& Lobo (2015). Também para os verbos que não aceitam a subida de clítico parece haver desenvolvimento na gramática infantil. Ainda assim, ambos os grupos de crianças mostraram já ser sensíveis à distinção entre verbos de subida opcional, com os quais a subida foi maioritária, e verbos de subida desfavorável, com os quais a subida foi minoritária. Para além disso, enquanto, nos verbos de subida opcional, há participantes que têm subida categórica, isso nunca aconteceu com os verbos de subida desfavorável, em que a não subida é geralmente preferida à subida. 
Concluímos, assim, que o conhecimento das restrições à subida de clítico e dos diferentes domínios de complementação infinitiva é gradual, o que é esperado, uma vez que envolve desenvolvimento lexical, ao contrário do que acontece com os domínios participiais mais defetivos, em que a subida é categórica e não está dependente de propriedades lexicais.

\section{iv) Em contextos de subida opcional, qual das posições é preferida pelas crianças?}

Nos contextos de subida opcional, verificamos que as crianças preferem, em geral, a subida à não subida. Estes resultados vão ao encontro do que foi descrito para a aquisição do espanhol por Eisenchlas (2003). Verificamos, contudo, no teste de produção induzida, que parece haver uma diminuição das taxas de subida do grupo pré-escolar para o escolar, e taxas mais baixas de subida no grupo dos adultos.

Uma das hipóteses possíveis para explicar a diminuição da taxa de subida é que haja algum efeito da norma no grupo de crianças em idade escolar e nos adultos. Como referimos na secção 2.1., as construções com subida de clítico são geralmente desaconselhadas na tradição gramatical normativa e, em particular, em contexto escolar. $\mathrm{O}$ teste de produção induzida, sendo uma tarefa condicionada, pode ter levado a um maior efeito de influência da norma do que acontece na produção espontânea.

Os resultados parecem evidenciar a influência do fator escolarização, uma vez que apresentam tendências diferentes para a mesma faixa etária (6 anos) em função do grupo (pré-escolar vs. escolar). O que se verifica são taxas de subida superiores no grupo pré-escolar em oposição ao escolar. Enquanto no grupo pré-escolar a subida corresponde a $64 \%$ (54\% em contexto de ênclise e $73 \%$ em contexto de próclise), no grupo escolar a mesma situa-se nos 52\% (45\% em contexto de ênclise e $60 \%$ em contexto de próclise). Tal parece comprovar tanto a influência da tradição normativa, como a do fator escolarização, que veicula a norma.

Consideremos agora a questão da complexidade, discutida em 2.2.2., como fator explicativo para a preferência pela subida de clítico na gramática das crianças. Se o desenvolvimento gramatical refletir uma escala de complexidade, então a aquisição do fenómeno de subida de clítico no português europeu parece apoiar a hipótese de que as estruturas com subida de clítico são, de alguma forma, menos complexas do que as estruturas sem subida de clítico. Note-se que uma noção de complexidade que considere o número de operações de Merge envolvidas, na linha de Jakubowicz (2011), não prevê que as estruturas com subida de clítico sejam mais simples do que as estruturas sem subida de clítico. A menor complexidade das estruturas com subida de clítico pode dever-se, por um lado, ao facto de as crianças terem preferência por estruturas com domínios infinitivos mais defetivos e, por outro lado, ao facto de as crianças preferirem legitimar o clítico num domínio finito. A ideia de que as crianças preferem estruturas mais defetivas contraria o que é assumido em Santos, Gonçalves \& Hyams (2016). Como referido acima, neste trabalho, as autoras defendem que as crianças preferem estruturas infinitivas funcionalmente mais complexas, em que o verbo seleciona um único argumento interno infinitivo, com um sujeito legitimado internamente a esse domínio. Contudo, as estruturas de subida de clítico que considerámos diferem das que foram consideradas no estudo de Santos, Gonçalves \& Hyams (2016): todos os verbos têm um único complemento ou argumento interno, que é uma estrutura infinitiva. Assim sendo, pode considerar-se que, neste caso, entre uma estrutura menos complexa e uma mais complexa,sem que haja variação no número de argumentos internos selecionados pelo verbo e sem que se coloquem questões de legitimação do sujeito da infinitiva, a criança possa preferir a menos complexa. Em alternativa, é plausível supor que a legitimação do clítico num domínio finito seja uma estratégia menos marcada para a criança, o que poderá levar a uma preferência pela construção com subida de clítico relativamente à construção sem subida de clítico.

Finalmente, podemos concluir que a variação encontrada quer individualmente, quer em cada grupo nas preferências por subida de clítico é compatível com uma análise das estruturas de restruturação na linha de Gonçalves (1999), em que pode haver diferentes graus de defetividade dos domínios infinitivos, o que requer algum tempo de estabilização e mais facilmente dá conta de variação individual. 


\section{Conclusões}

Neste trabalho, considerámos dados de um teste de produção induzida e dados de produção espontânea de crianças e adultos para estudar o fenómeno de subida de clítico no português. Concluímos que:

i) a subida de clítico é adquirida cedo no português europeu, à semelhança do que foi descrito para o espanhol - emerge antes dos 3 anos nos dados de produção espontânea e é a estratégia preferencial;

ii) existe um desenvolvimento progressivo das propriedades lexicais associadas aos verbos que aceitam/não aceitam a subida - aos 8 anos, as crianças ainda produzem alguma subida de clítico com verbos de subida desfavorável, ainda que mostrem já sensibilidade às diferenças entre verbos de subida opcional e verbos de subida desfavorável;

iii) há sensibilidade à presença de proclisador como elemento facilitador da subida de clítico - em todos os grupos, as taxas de subida de clítico são superiores quando está presente a negação;

iv) há preferência pelas construções com subida de clítico com verbos de subida opcional nas crianças mais novas, o que leva a crer que esta estrutura possa ser menos complexa para as crianças.

Os dados da aquisição permitem ainda apoiar uma análise das estruturas de restruturação determinada pelas propriedades de seleção dos verbos e associada à defetividade estrutural do complemento infinitivo selecionado.

\section{Agradecimentos}

Agradecemos ao Colégio O Nosso Jardim e ao Colégio Valsassina a disponibilidade para nos receberem, bem como às crianças que participaram no estudo e aos seus pais.

Agradecemos ainda aos participantes no Encontro da Associação Portuguesa de Linguística em que este trabalho foi apresentado pelas suas contribuições, que nos permitiram refletir sobre este trabalho e melhorá-lo, e aos revisores deste artigo pelas suas sugestões.

\section{Referências}

Agathocleous, Marina, Alexandra Charalambous, Elena Papadopoulou \& Kleanthes K. Grohmann (2014) The Role of the Social Environment on Linguistic Development: A View from Cypriot Greek Clitic Placement. In Kleanthes K. Grohmann \& Theoni Neokleous (eds.) Developments in the Acquisition of Clitics. Newcastle-upon-Tyne: Cambridge Scholars Publishing, pp. 42-87.

Cardinaletti, Anna \& Ur Shlonsky (2004) Clitic Positions and Restructuring in Italian. Linguistic Inquiry, $35: 4$, pp. 519-557.

Cinque, Guglielmo (2004) 'Restructuring' and functional structure. In Adriana Belletti (ed.) Structures and Beyond: The Cartography of Syntactic Structures. Oxford/NewYork: Oxford University Press, pp. 132191.

Cinque, Guglielmo (2006) Restructuring and Functional Heads: the Cartography of Syntactic Structures, vol. 4. Oxford: Oxford University Press.

Costa, João, Alexandra Fiéis \& Maria Lobo (2015) Input variability and late acquisition: clitic misplacement in European Portuguese. Lingua 61, pp. 10-26.

Costa, João \& Maria Lobo (2007) Complexidade e omissão de clíticos: o caso dos reflexos. XXII Encontro Nacional da Associação Portuguesa de Linguística. Textos Seleccionados. Lisboa: APL, pp. 303-313. 
Duarte, Inês (2003) Padrões de colocação dos pronomes clíticos. In Mateus et al. Gramática da Língua Portuguesa. 5a. ed. Lisboa: Ed. Caminho, pp. 847-867.

Duarte, Inês \& Gabriela Matos (2000) Romance Clitics and the Minimalist Program. In J. Costa, (ed.) Portuguese Syntax. New Comparative Studies. Oxford: Oxford University Press, pp. 116-142.

Duarte, Inês, Gabriela Matos \& Isabel Faria (1995) Specificity of European Portuguese Clitics in Romance. In I. Hub Faria \& M. J. Freitas (eds.) Studies on the Acquisition of Portuguese. Lisboa: APL/Colibri, pp. 129154.

Eisenchlas, Susana (2003) Clitics in child Spanish. First Language 23 (2), pp. 193-211.

Fiéis, Alexandra \& Ana Madeira (2012) Predicados de controlo na diacronia do português. In Armanda Costa, Cristina Flores \& Nélia Alexandre (eds.) Textos Selecionados do XXVII Encontro da Associação Portuguesa de Linguística. Lisboa: APL, pp. 271-284.

Fiéis, Alexandra, Ana Madeira \& Maria Francisca Xavier (2013) Clitic climbing in L2 Portuguese. In J. Cabrelli Amaro, T. Judy \& D. Pascual y Cabo (eds.) Proceedings of the 12th Generative Approaches to Second Language Acquisition Conference (GASLA 12). Somerville, MA: Cascadilla Proceedings Project, pp. 39-49.

Gonçalves, Anabela (1999) Predicados Complexos Verbais em Contextos de Infinitivo não Preposicionado do Português Europeu. Dissertação de doutoramento, Universidade de Lisboa.

Gonçalves, Anabela (2002) Verbos auxiliares e verbos de reestruturação do Português Europeu. In Duarte, Isabel Margarida, Joaquim Barbosa, Sérgio Matos \& Thomas Hüsgen (eds.) In Actas do Encontro Comemorativo dos 25 Anos do Centro de Linguística da Universidade do Porto. Porto: Centro de Linguística da Universidade do Porto. Vol. 2, pp. 45-57.

Grohmann, Kleanthes K. \& Evelina Leivada (2012) Interface ingredients of dialect design. Bi-x, socio-syntax of development, and the grammar of Cypriot Greek. In Anna Maria Di Sciulio (ed.) Towards a Biolinguistic Understanding of Grammar. Essays on Interfaces. John Benjamins, pp. 239-262.

Grüter, Therese (2006) Object clitics and null objects in the acquisition of French. PhD diss., McGill Univ. Montreal.

Guasti, Maria Teresa (1993/94) Verb syntax in Italian child grammar: finite and nonfinite verbs. Language Acquisition. 3 (1), pp. 1-40.

Guasti, Maria Teresa (2002) Language Acquisition. The Growth of Grammar. Cambridge Mass.: MIT Press.

Hamann, Cornelia, \& Adriana Belletti (2006) Developmental patterns in the acquisition of complement clitic pronouns. Comparing different acquisition modes with an emphasis on French. Rivista di Grammatica Generativa, 31, pp. 39-78.

Hamann, Cornelia, Luigi Rizzi \& U. H. Frauenfelder (1996) On the acquisition of subject and object clitics in French. In H. Clahsen, ed. Generative perspectives on language acquisition. Amsterdam: John Benjamins, pp. 309-34.

Haverkort, J. M. W. (1993) Clitics and Parametrization: Case Studies in the Interaction of Head Movement Phenomena. Diss. Doutoramento. Univ. Católica de Brabant.

Jakubowicz, Celia (2011) Measuring derivational complexity: New evidence from typically developing and SLI learners of L1 French. Lingua, 121.3, pp. 339-351.

Kayne, Richard (1989) Null subjects and clitic climbing. In Osvaldo Jaeggli \& Kenneth Safir (eds.) The Null Subject Parameter. Dordrecht: Reidel, pp. 239-261.

Kirby, Susannah (2011) Move over, Control freaks: Syntactic Raising as a cognitive default. BUCLD 35 Proceedings Supplement.

Marinis, Theo (2000) The acquisition of clitic objects in Modern Greek: Single clitics, clitic doubling, clitic left dislocation. In ZAS Papers in Linguistics 15. Berlin: ZAS, pp. 259-81. 
Martins, Ana Maria (2000) A Minimalist Approach to Clitic Climbing. In João Costa (org.) Portuguese Syntax: New Comparative Studies. Oxford \& New York: Oxford University Press, pp. 169-190.

Martins, Ana Maria (2013) Posição dos Pronomes Pessoais clíticos. In E. B. P. Raposo et al., (orgs.) Gramática do Português. Vol. II. Lisboa: Fundação Calouste Gulbenkian, pp. 2231-2302.

Pérez-Leroux, Ana Teresa, Alejandro Cuza \& Danielle Thomas (2011) Clitic placement in Spanish/English bilingual children. Bilingualism: Language and Cognition, 14(2), pp. 221-232.

Rizzi, Luigi (1982) Issues in Italian Syntax. Dordrecht, Foris.

Rodríguez-Mondoñedo, Miguel, William Snyder \& Koji Sugisaki (2006) Clitic-climbing in child Spanish and the theory of parameters. In Alejna Brugos, Manuella R. Clark-Cotton \& Seungwan Ha (eds.) $A$ Supplement to the Proceedings of the 29th Boston University Conference on Language Development.

Santos, Ana Lúcia, Michel Généreux, Aida Cardoso, Celina Agostinho \& Silvana Abalada (2014) A corpus of European Portuguese child and child-directed speech. In Proceedings of the 9th Conference on Language Resources and Evaluation - LREC 2014, European Language Resources Association (ELRA), pp. 14881491.

Santos, Ana Lúcia, Anabela Gonçalves, \& Nina Hyams (2016) Aspects of the acquisition of object control and ECM-type verbs in European Portuguese. Language Acquisition, 23(3), pp. 199-233. Publicado online 2015. DOI: 10.1080/10489223.2015.1067320.

Vitorino, Inês (2017) Aquisição de Estruturas com Subida de Clítico em Português Europeu. Dissertação de mestrado em Ciências da Linguagem. Faculdade de Ciências Sociais e Humanas, Universidade Nova de Lisboa.

Wexler, Kenneth, Anna Gavarró \& Vicens Torrens (2004) Feature checking and object clitic omission in child Catalan and Spanish. In R. Bok-Bennema, B. Hollebrandse, B. Kampers-Manhe \& P. Sleeman, eds. Romance Languages and Linguistic Theory 2002. Amsterdam: John Benjamins, pp. 253-68.

Wexler, Kenneth (1998) Very early parameter setting and the unique checking constraint: A new explanation of the optional infinitive stage. Lingua 106, pp. 23-79.

Wurmbrand, Susanne (2003 [2001]) Infinitives. Restructuring and Clause Structure. Berlin/New York: Mouton de Gruyter.

Wurmbrand, Susanne (2006) Verb Clusters, Verb Raising and Restructuring. In Martin Everaert \& Henk Riemsdijk, eds. The Blackwell Companion to Syntax, vol. V. Oxford: Blackwell, pp. 229-343. 